\title{
Surveillance for Antibodies to Leishmania spp. in Dogs from Sri Lanka
}

Author(s): A. C. Rosypal , S. Tripp , C. Kinlaw, S. Hailemariam , R. R. Tidwell , D. S. Lindsay , R. P. V. J. Rajapakse , C. Sreekumar, and J. P. Dubey

Source: Journal of Parasitology, 96(1):230-231. 2010.

Published By: American Society of Parasitologists

DOI: http://dx.doi.org/10.1645/GE-2288

URL: http://www.bioone.org/doi/full/10.1645/GE-2288

BioOne (www.bioone.org) is a nonprofit, online aggregation of core research in the biological, ecological, and environmental sciences. BioOne provides a sustainable online platform for over 170 journals and books published by nonprofit societies, associations, museums, institutions, and presses.

Your use of this PDF, the BioOne Web site, and all posted and associated content indicates your acceptance of BioOne's Terms of Use, available at www.bioone.org/page/terms_of use.

Usage of BioOne content is strictly limited to personal, educational, and non-commercial use. Commercial inquiries or rights and permissions requests should be directed to the individual publisher as copyright holder. 
American Society of Parasitology. A. C. Rosypal, S. Tripp, C. Kinlaw, S. Hailemariam, R. R. Tidwell, D. S. Lindsay, R. P. V. J. Rajapakse, C. Sreekumar, and J. P. Dubey (2010). "Surveillance for Antibodies to Leishmania spp. in Dogs from Sri Lanka," Journal of Parasitology, Vol. 96, No. 1, pp. 230-231. doi: http://dx.doi.org/10.1645/GE-2288

J. Parasitol., 96(1), 2010, pp. 230-231 (C) American Society of Parasitologists 2010

\title{
Surveillance for Antibodies to Leishmania spp. in Dogs From Sri Lanka
}

\begin{abstract}
A. C. Rosypal, S. Tripp, C. Kinlaw, S. Hailemariam, R. R. Tidwell†, D. S. Lindsay $\neq$, R. P. V. J. Rajapakse $§$, C. Sreekumar $\|$, and J. P. Dubey\#, Department of Natural Sciences and Mathematics, College of Science, Technology, Engineering and Mathematics, Johnson C. Smith University, 100 Beatties Ford Rd., Charlotte, North Carolina, 28216; *Department of Natural Sciences and Mathematics, College of Arts and Sciences, Shaw University, Raleigh, North Carolina, 27601; †School of Medicine, Department of Pathology and Laboratory Medicine, CB \#7525, Room 805 Brinkhous-Bullitt Building, University of North Carolina at Chapel Hill, Chapel Hill, North Carolina 25799; łCenter for Molecular Medicine and Infectious Diseases, Department of Biomedical Sciences and Pathology, Virginia-Maryland Regional College of Veterinary Medicine, Virginia Tech, 1410 Prices Fork Road, Blacksburg, Virginia 24061; §Department of Veterinary Pathobiology, Faculty of Veterinary Medicine and Animal Science, University of Peradeniya, Peradeniya, Sri Lanka; \|Department of Parasitology, Madras Veterinary College, Tamil Naidu Veterinary and Animal Sciences University, Chennai-600007, India; \#United States Department of Agriculture, Agricultural Research Service, Animal and Natural Resources Institute, Animal Parasitic Diseases Laboratory, Building 1001, Beltsville, Maryland 20705-2350. e-mail: acrosypal@jcsu.edu
\end{abstract}

ABSTRACT: The global distribution of leishmaniasis is rapidly expanding into new geographic regions. Dogs are the primary reservoir hosts for human visceral leishmaniasis caused by infection with Leishmania infantum. Natural infections with other Leishmania spp. can occur in dogs, but their role as reservoir hosts for other species of Leishmania is uncertain. Leishmania donovani is traditionally considered a visceralizing anthroponotic species; however, cutaneous leishmaniasis caused by $L$. donovani has been reported in Sri Lanka. In the present study, sera from 114 dogs in Sri Lanka were examined for antibodies to visceralizing Leishmania spp. Sera were tested by the canine immunochromatographic strip assays based on recombinant K39 antigen. Anti-Leishmania spp. antibodies were detectable in 1 of $114(0.9 \%)$ dogs from Sri Lanka. Nonetheless, serological evidence suggests that leishmaniasis may be an emerging zoonosis in Sri Lanka.

Visceral leishmaniasis (VL) is a systemic sand fly-vectored disease caused by infection with protozoan parasites in the Leishmania donovani complex, which includes Leishmania infantum. Zoonotic VL, caused by infection with $L$. infantum, is endemic in the Americas, the Mediterranean basin, and parts of Asia, including China and the Middle East (Dereure et al., 2003). The domestic dog is the primary reservoir host for human cases of zoonotic VL. In the Indian subcontinent and East Africa, anthroponotic VL results from $L$. donovani (sensu stricto) transmission from human to insect vector to human. However, although $L$. donovani is generally considered a viscerotropic parasite, it has also been sporadically implicated in cases of cutaneous leishmaniasis in India and Sri Lanka (Karunaweera et al., 2003; Nawaratna et al., 2009; Sharma et al., 2009). Recently, in Sri Lanka, increasing numbers of cutaneous leishmaniasis caused by $L$. donovani infection have been reported and there is limited evidence suggesting that it may be a zoonotic form of the disease (Nawaratna et al., 2009). Leishmaniasis has been reported in regions of the world where it was not found previously (Rosypal et al., 2003; Shaw, 2007). Several factors influence the increased incidence of VL, including human migration, HIV co-infection, and climate change (Chappuis et al., 2007; Shaw, 2007).

Evolutionary history suggests that species of Leishmania have a zoonotic origin and that certain species, including $L$. donovani, have adapted to anthroponotic transmission cycles (Kerr, 2000; Kerr et al., 2000; Shaw, 2007). Anthroponotic VL is caused by infection with $L$. donovani and, moreover, dogs are generally not considered to be involved in the transmission cycle of this parasite to humans. Natural infection of dogs with $L$. donovani can, however, occur (Dereure et al., 2003), but the status of the domestic dog as a reservoir is unclear (Dantas-Torres, 2007). The purpose of the present study was to determine the prevalence of antibodies to visceralizing Leishmania parasites in canine populations from Sri Lanka.

In this investigation, 114 street dogs were captured in Sri Lanka and killed by overdose injection of sodium thiopentonel. Both male and female mixed-breed dogs of varying ages were included in the study group. Information on individual dogs was not available. Blood samples were collected at necropsy as part of prevalence studies for Toxoplasma gondii (Dubey et al., 2007); refrigerated serum was sent by air to the United

DOI: $10.1645 / G E-2288$
States Department of Agriculture Animal Parasitic Diseases Laboratory, Beltsville, Maryland, in March and June 2006. Serum samples were stored at $-20 \mathrm{C}$, and frozen sera were subsequently sent to the Department of Pathology and Laboratory Medicine, School of Medicine, University of North Carolina at Chapel Hill, Chapel Hill, North Carolina. Further serologic testing was conducted at Shaw University, Raleigh, North Carolina, and Johnson C. Smith University, Charlotte, North Carolina.

The commercially available immunochromatographic (ICT) dipstick assay was performed for qualitative detection of antibody to visceralizing Leishmania spp. Antibody testing was performed according to the manufacturer's test procedure (Kalazar Detect Canine Rapid Test, InBios International Ltd., Seattle, Washington). The ICT assay is based on recombinant antigens and has been developed into a dipstick format. The tests are based on recombinant antigens for which previous reports have demonstrated superior performance over traditional serological screening tests based on crude antigens or whole organisms (Scalone et al., 2002). Canine sera were tested for antibodies to recombinant K39 (rK39), which is an amastigote protein specific to visceralizing Leishmania spp. (Burns et al., 1993). The ICT detects antibodies to $L$. infantum and $L$. donovani, which are both parasites in the $L$. donovani complex.

Of the 114 Sri Lanka dogs assayed, $1(0.9 \%)$ had detectable antiLeishmania sp. antibodies. There are several serological methods used for detection of Leishmania sp.-specific antibodies, including the indirect fluorescent antibody test (IFAT), complement fixation, direct agglutination, enzyme-linked immunosorbent assay, and ICT dipstick test (Rosypal et al., 2003; Lira et al., 2006). The IFAT is the most commonly used of all serological assays and represents the "gold standard" with which other serological tests are compared (Rosypal et al., 2003) Serological tests are not $100 \%$ sensitive and specific; however, several studies using the recombinant antigens in the ICT demonstrated high specificity compared to traditional serological assays (Burns et al., 1993; Rosypal et al., 2005, 2007). In addition, the ICT assay used in the present study is now considered to be the best available test for field diagnosis of VL in remote geographic regions (Chappuis et al., 2007).

Cutaneous leishmaniasis caused by $L$. donovani infection can occasionally occur, as in reports from Sri Lanka (Nawaratna et al., 2007), making further investigation necessary for Sri Lankan $L$. donovani. Multilocus enzyme electrophoresis characterized cutaneous $L$. donovani strains from Sri Lanka as zymodeme MON-37 (Karunaweera et al., 2003), which differs from India, where VL is predominantly caused by $L$. donovani zymodeme MON-2. DNA sequencing and microsatellite analyses demonstrated that Indian and Sri Lankan $L$. donovani strains are genetically similar, but highlighted the important biological differences between geographically close parasites (Siriwardana et al., 2007).

There are at least 15 Leishmania spp. that are pathogenic for humans and 13 are well-recognized zoonotic parasites (Gramiccia and Gradoni, 2005). Only 2 species, L. tropica and L. donovani, are traditionally considered to be anthroponotic organisms. Moreover, there is disagreement over the transmission dynamics of these 2 species since natural infections in animal reservoir hosts have been documented in endemic areas (reviewed by Gramiccia and Gradoni, 2005). In Asia and other parts of the world, dogs are primary reservoir hosts of $L$. infantum, although canine infection is possible with $L$. donovani (Dereure et al., 2003), the causative agent of human VL in India. Indeed, biological differences among geographically distinct isolates of a single Leishmania sp. and 
zymodemes have been described (Cupolillo et al., 2003; Rosypal et al., 2005).

We investigated the prevalence of antibodies to visceralizing Leishmania sp. parasites in a canine population from Sri Lanka. Results from our study support previous work, suggesting that leishmaniasis may be an emerging zoonosis in Sri Lanka. Although the presence of Leishmania sp. antibodies in a single dog is insufficient to confirm a canine reservoir, further studies should be conducted to elucidate the role of dogs in Sri Lankan leishmaniasis.

This work was supported by a grant from the Bill and Melinda Gates Foundation to R.R.T. The contribution of S. T. and C. K. was funded by a mini-grant to A.C.R. from the Historically Black Universities and Colleges-Undergraduate Program (HBCU-UP) at Johnson C. Smith University.

\section{LITERATURE CITED}

Burns, J. M. Jr., W. G. Shreffler, D. R. Benson, H. W. Ghalib, R. Badaro, and S. G. Seed. 1993. Molecular characterization of a kinesin-related antigen of Leishmania chagasi that detects specific antibody in African and American visceral leishmaniasis. Proceedings of the National Academy of Sciences U S A 99: 775-779.

Chappuis, F., S. Sundar, A. Hailu, H. Ghalib, S. Rijal, R. W. Peeling, J. Alvar, and M. Boelart. 2007. Visceral leishmaniasis: What are the needs for diagnosis, treatment and control? Nature Reviews Microbiology 5: S7-S16.

Cupolillo, E., L. R. Brahim, C. B. Toaldo, M. P. de Oliveira-Neto, A. Falqueto, M. de Farias Naiff, and G. Grimaldi, Jr. 2003. Genetic polymorphism and molecular epidemiology of Leishmania (Vianna) braziliensis from different hosts and geographic areas in Brazil. Journal of Clinical Microbiology 41: 3126-3132.

Dantas-Torres, F. 2007. The role of dogs as reservoirs of Leishmania parasites, with emphasis on Leishmania (Leishmania) infantum and Leishmania (Viannia) braziliensis. Veterinary Parasitology 149: 139146.

Dereure, J., S. H. El-Safi, B. Bucheton, M. Boni, M. M. Kheir, B. Davoust, F. Pratlong, E. Feugier, M. Lambert, A. Dessein, and J. P. Dedet. 2003. Visceral leishmaniasis in eastern Sudan: Parasite identification in humans and dogs; host-parasite relationships. Microbes and Infection 5: 1103-1108.

Dubey, J. P., R. P. V. J. Rajapakse, R. R. M. K. K. W. Wijesumdera, N. Sundar, G. V. Velmuraan, O. C. H. Kwok, and C. Su. 2007. Prevalence of Toxoplasma gondii in dogs from Sri Lanka and genetic characterization of the parasite isolates. Veterinary Parasitology 146: 331-346.

Gramiccia, M. and L. Gradoni. 2005. The current status of zoonotic leishmaniases and approaches to disease control. International Journal for Parasitology 35: 1169-1180.

Karunaweera, N. D., R. Merkelz, and C. MacKinnon. 2000. Further support for a Palaearctic origin of Leishmania. Memórias do Instituto Oswaldo Cruz 95: 579-581.
, F. Pratlong, H. V. Y.D. Siriwardane, R. L. Ihalamulla, and J. P. Dedet. 2003. Sri Lankan cutaneous leishmaniasis is caused by Leishmania donovani zymodeme MON-37. Transactions of the Royal Society of Tropical Medicine and Hygiene 97: 380-381.

Kerr, S. F. 2000. Palaearctic origin of Leishmania. Memórias do Instituto Oswaldo Cruz 95: 75-80.

Lira, R. A., M. Paiva Cavalcanti, M. Nakazawa, A. G. P. Ferreira, E. D. Silva, F. G. C. Abath, L. C. Alves, W. V. Souza, and Y. M. GoMEs. 2006. Canine visceral leishmaniasis: a comparative analysis of the EIE-leishmaniose-visceral-canina-Bio-Manguinhost and the IFIleishmaniose-visceral-canina-Bio-Manguinhost kits. Veterinary Parasitology 137: 11-16.

Nawaratna, S. S., D. J. Weilgama, and K. Rajapaksha. 2009. Cutaneous leishmaniasis in Sri Lanka: A study of possible animal reservoirs. International Journal of Infectious Diseases 13: 513-517.

- C. J. Wijekoon, M. Dissanayake, and K. Rajapaksha. 2007. Cutaneous leishmaniasis, Sri Lanka. Emerging Infectious Diseases 13: 1068-1070.

Rosypal, A. C., R. R. Tidwell, and D. S. Lindsay. 2007. Prevalence of antibodies to Leishmania infantum and Trypanosoma cruzi in wild canids from South Carolina. Journal of Parasitology 93: 955957.

G. C. Troy, R. B. Duncan, JR., A. M. ZajaC, and D. S. Lindsay. 2005. Utility of diagnostic tests used in diagnosis of infection in dogs experimentally inoculated with a North American isolate of Leishmania infantum. Journal of Veterinary Internal Medicine 19: 802-809.

, A. M. ZaJaC, AND D. S. Lindsay. 2003. Canine visceral leishmaniasis and its emergence in the United States. Veterinary Clinics of North America Small Animal Practice 33: 921-937.

Scalone, A., R. Deluna, G. Oliva, L. Baldi, G. Satta, G. Vesco, W. Mignone, C. Turilli, R. Mondesire, R. Simpson, et Al. 2002. Evaluation of the Leishmania recombinant K39 antigen as a diagnostic marker for canine leishmaniasis and validation of a standardized enzyme-linked immunosorbent assay. Veterinary Parasitology 104: 275-285.

Sharma, N. L., V. K. Mahajan, A. K. Negi, and G. K. Verma. 2009. The rK39 immunochromatic dipstick testing: A study for K39 seroprevalence in dogs and human leishmaniasis patients for possible animal reservoir of cutaneous and visceral leishmaniasis in endemic focus of Satluj River Valley of Himachal Pradesh (India). Indian Journal of Dermatology, Venerology, Leprology 75: 52-55.

Shaw, J. 2007. The leishmaniasis-survival and expansion in a changing world. A mini-review. Memórias do Instituto Oswaldo Cruz 102: 541-547.

Siriwardana, H. V. Y. D., H. A. Noyes, N. J. Beeching, M. L. Chance, N. D. Karunaweera, and P. A. Bates. 2007. Leishmania donovani and cutaneous leishmaniasis, Sri Lanka. Emerging Infectious Diseases 13: 476-478. 